\title{
RESISTÊNCIA E PRÁXIS NA GREVE DOS PROFESSORES DA REDE PÚBLICA MUNICIPAL DO RIO DE JANEIRO
}

\author{
RESISTANCE AND PRAXIS IN THE STRIKE OF THE TEACHERS OF \\ THE RIO DE JANEIRO MUNICIPAL NETWORK
}

\begin{abstract}
Laís Oliveira de Souza iD) (https://orcid.org/0000-0002-4947-1220) ${ }^{1}$, José Augusto Pina iD) (http://orcid.org/0000-00033204-2240) ${ }^{2}$, Katia Reis de Souza iD (https://orcid.org/0000-0002-2084-2606) ${ }^{2}$
${ }^{1}$ Fundação Oswaldo Cruz, Escola Nacional de Saúde Pública Sergio Arouca, Rio de Janeiro, RJ, Brasil. $<$ lais.seso@gmail.com>
${ }^{2}$ Fundação Oswaldo Cruz, Escola Nacional de Saúde Pública Sergio Arouca, Centro de Estudos da Saúde do Trabalhador e Ecologia Humana, Rio de Janeiro, RJ, Brasil.

Resumo Este estudo tem por objetivo analisar as relações entre trabalho, educação e saúde na greve dos profissionais de educação da rede municipal do Rio de Janeiro, ocorrida no ano de 2013. Trata-se de uma pesquisa qualitativa, a qual adotou, como técnica de investigação, a realização de entrevistas individuais e a pesquisa documental, com base na imprensa sindical. Foi escolhida a técnica de análise temática, e foram identificados três temas principais de interpretação, a saber: trabalho e defesa da educação pública de qualidade; aprendizado coletivo e pedagogia da luta; e luta coletiva pela saúde. No ângulo de compreensão da história, a greve materializou-se como espaço de questionamento acerca da situação do trabalho nas escolas e como movimento de luta em defesa da educação pública de qualidade. Do mesmo modo, a greve trouxe reflexões acerca da relação entre o trabalho docente e a luta pela saúde. Conclui-se que ações coletivas de trabalhadores são espaços de aprendizagem, de produção de conhecimento e intervenção em saúde. Trata-se de uma perspectiva ampliada de educação e saúde, como práxis pedagógica, que se processa na luta e na valorização da experiência coletiva do trabalho.

Palavras-chave saúde do trabalhador; professores; educação pública; sindicato; greve.

\begin{abstract}
The aim of the present study was to analyze the relationships between work, education and health in the strike of the education professionals of the Rio de Janeiro (Brazil) municipal network, in the year of 2013. This is a qualitative research, which adopted individual interviews and documentary research as its investigation technique, based on the trade union press. We chose the thematic analysis technique, and three main themes of interpretation were identified: work and defense of quality public education; collective learning and struggle pedagogy; and collective fight for health. From the angle of the historical understanding of the event, the strike materialized as a space for questioning the situation of work in schools and as a movement of struggle in defense of quality public education. Likewise, the strike raised reflections about the relationship between teaching as an occupation and the struggle for health. The conclusion is that the collective actions of workers are spaces of learning, of production of knowledge, and of intervention in health. It is an extended perspective of education and health, as a pedagogical praxis, which is carried out in the struggle and in the valorization of the collective experience of work.
\end{abstract}

Keywords workers health; teachers; public education; union; strike. 


\section{Introdução}

No Brasil, entre os anos de 1970 e 1980, a ampliação do acesso à educação pública provocou mudanças no processo de trabalho e na estrutura de remuneração dos profissionais da educação. Vivia-se um período de crise financeira do Estado, o que significou rebaixamento salarial e precarização social do trabalho de professores. Em consequência, surge a questão da ampliação da jornada laboral: o docente se viu obrigado a assumir mais de um emprego ou a duplicar a jornada na própria rede de ensino por necessidade de complementação salarial. Esse panorama agrava-se a partir da década de 1990, momento em que a educação sofreu grandes mudanças em função das políticas neoliberais de ajuste econômico. Tais políticas trouxeram graves implicações sociais, aprofundando a degradação das condições de vida e de trabalho de seus profissionais. Nesse período, as escolas públicas também passaram a organizar a gestão do trabalho por modelos gerenciais, com a adoção de critérios de avaliação que mensuram o trabalho por produtividade e estimulam a competitividade entre os próprios trabalhadores. Restringe-se a educação e, por conseguinte, o trabalhador, a fatores de produtividade (Leher, Vittoria e Motta, 2017; Souza e Brito, 2012).

Em termos históricos, trata-se de uma nova configuração do trabalho docente, resultado de transformações gerais ocorridas no mundo do trabalho sob a égide do capital. Assunção e Oliveira (2009) afirmam que professores se veem, atualmente, compelidos a responder a múltiplas demandas as quais, na maioria das vezes, resultam na solicitação cada vez maior de suas energias e saúde. Segundo as autoras, o trabalho do professor ultrapassa - e muito - o espaço de sala de aula e estende-se às relações com a comunidade, à gestão da escola, ao planejamento do projeto pedagógico e à participação em conselhos, entre outras funções. Nesse sentido, esses profissionais sentem-se obrigados a dominar novos saberes, excedendo a sua jornada formal e suscitando a intensificação do trabalho.

Estudos realizados por Souza e colaboradores (2003), Neves e Silva (2006) e Souza e Rozemberg (2013) ressaltam problemas variados acerca do trabalho em escolas. Entre eles, podem-se citar: gestão centralizada e autoritária, extensa jornada de trabalho, inexistência de pausas no trabalho, infraestrutura precária, escassez de funcionários, sobrecarga de trabalho, baixos salários e pouco reconhecimento social. De mais a mais, esses estudos fazem referência a outras questões que podem contribuir para a compreensão dos componentes qualitativos da saúde dos profissionais da educação, tais como as políticas governamentais em educação. $O$ ponto que se quer ressaltar diz respeito ao quadro de precarização das escolas que compõem o sistema de educação pública no Brasil. Além disso, observa-se o modo como os sucessivos governos têm desconsiderado a área da educação, ou seja, com insuficiente dotação 
de recursos proveniente de uma política de austeridade fiscal. Assim, parece acertado afirmar que tal situação tem sido decisiva para a deterioração do sistema escolar, bem como do processo de saúde e doença dos profissionais da educação. De fato, estudos apontam para a escola como um espaço potencializador de agravos à saúde e gerador de sofrimento e mal-estar para os que nela trabalham (Brito e Athayde, 2003; Marchiori, Barros e Oliveira, 2005; Mascarello e Barros, 2007; Assunção e Oliveira, 2009 e Souza, 2014).

Complementarmente, o estudo de Neves e Silva (2006) mostra a presença significativa de mal-estar vivenciado pelas professoras e evidenciado por sinais generalizados de sofrimento, sufocamento, estresse, esgotamento, ansiedade, depressão e fadiga no trabalho. Gomes e Brito (2006) somam, a esses indícios, falta de ar, tonturas, labirintite, perturbações do sono, problemas vocais, problemas respiratórios, alergias e queixas relacionadas ao aparelho digestivo. Além do mais, as autoras referem-se a uma potencialização desse conjunto de problemas em determinadas épocas do ano, como o fim do período letivo. Quanto a este último tópico, Souza e Brito (2013) mostraram que, a partir de agosto, aumentam as queixas de saúde dos trabalhadores relacionadas ao aumento de tarefas nas escolas. É comum professores referirem-se ao mal-estar sentido nesse período com expressões que simbolizam o agrupamento de um conjunto de sintomas cujas características revelam sua situação de saúde de forma caricata: “agostite, setembrite, outubrite" (Souza e Brito, 2013, p. 273). As autoras destacam que predominam saídas individuais para enfrentar as adversidades do trabalho e problemas de saúde em detrimento de formas coletivas de resistência e mudanças das condições de trabalho em escolas.

Diferentemente, o presente estudo identificou e analisou modos de resistência e de defesa da saúde, de caráter coletivo, por parte dos profissionais da educação, ocorridos em um período recente da história; precisamente, durante os meses de agosto, setembro e outubro do ano de 2013. Trata-se de respostas coletivas frente às contradições do trabalho em escolas, originadas no cerne da organização dos trabalhadores. Fato é que, após uma fase de 19 anos sem greves ou paralisações, os profissionais da rede pública de educação do município do Rio de Janeiro surpreendem a sociedade com uma greve de massa, acompanhada de amplas e participativas assembleias e, ainda, de intensas mobilizações e passeatas pelas ruas da cidade. A greve teve início no dia 8 de agosto e durou até 25 de outubro de 2013, com um intervalo e suspensão ocorridos no período entre 11 e 19 de setembro.

No ano de 2013, a rede de educação municipal do Rio de Janeiro contava com 1.075 escolas e 364 espaços de desenvolvimento infantil e creches; 674.312 alunos e mais de 60.000 servidores, dos quais, 42.903 professores. Além de ser o maior segmento da categoria, pode-se afirmar que os professores foram aqueles que exerceram papel ativo e protagonista na organização e mobilização do conjunto dos profissionais da educação. Segundo o Sindicato Estadual dos 
Profissionais de Educação do Rio de Janeiro (Sepe-RJ, 2013a), no que concerne às reivindicações do movimento de greve, ganham destaque: reajuste salarial de 19\%; plano de carreira unificado; 1/3 de carga horária para o planejamento; fim da meritocracia; fim do projeto de reestruturação da rede municipal; questões pedagógicas e questões relativas aos funcionários administrativos.

A pauta de reivindicações expressa questionamentos do trabalho docente atinentes à política educacional. Ao mesmo tempo, este movimento pode ser analisado sob a perspectiva do aprendizado coletivo produzido por estes trabalhadores no decorrer da luta, transformando-o em processo pedagógico constitutivo da atividade de greve. Também se pode indagar acerca da relação entre o trabalho e a saúde dos trabalhadores nas escolas.

Desse modo, este estudo tem por objetivo analisar as relações entre trabalho, educação e saúde na greve dos profissionais de educação da rede municipal do Rio de Janeiro, no ano de 2013.

Não obstante, cumpre duas importantes observações acerca do delineamento deste estudo. Na primeira, a greve dos professores ocorreu poucos meses após as manifestações de junho de 2013, possivelmente influenciada pelo ambiente político suscitado por estas manifestações. Todavia, neste artigo, não há indagações acerca da relação entre estes dois acontecimentos. As diferentes explicações para os eventos de junho de 2013, inclusive opostas entre si, estão satisfatoriamente sintetizadas por Braga (2017). Quanto à segunda observação, refere-se à questão sindical. A greve foi dirigida pelo Sepe-RJ com enorme participação dos professores de base, inclusive com momentos de tensões entre a base da categoria e a direção sindical. No entanto, não foram analisadas essas diferenças - nem tampouco a diversidade de posicionamento das correntes sindicais presente na greve. Esses esclarecimentos colaboram para a delimitação do presente estudo e possibilitam que suas contribuições possam ser aprofundadas por outras investigações.

\section{Luta dos trabalhadores na construção do conhecimento e defesa da saúde}

Este estudo está ancorado na concepção de determinação histórica e social do processo saúde-doença, segundo autores da Medicina Social Latino-Americana (Laurell, 1985; Breilh, 1995), fundamentalmente relacionada às práticas sociais de classe e às formas de organização política na sociedade.

Por conseguinte, defende-se, nesta pesquisa, a tese segundo a qual o processo saúde-doença é fortemente determinado pela capacidade organizativa dos trabalhadores (Laurell e Noriega, 1989). E mais: o saber (da experiência coletiva) dos trabalhadores é indispensável à produção de conhecimento em saúde, tanto mais quando se pensa em intervenção na perspectiva de implementar mudanças no trabalho (Souza, 2014). Importa, ainda, considerar como imperativo para a construção do conhecimento e intervenção em saúde, no 
contexto da sociedade capitalista - e com a participação dos trabalhadores -, o enfrentamento das contradições relativas ao trabalho como ponto central de análise (Laurell e Noriega, 1989).

Em se tratando de movimento de greve, compreende-se este como expressão da resistência aberta e luta coletiva dos trabalhadores no enfrentamento aos conflitos do trabalho. Segundo Lênin (1961), a greve possibilita ensinamentos aos trabalhadores, ensina-os a unirem-se, a pensarem na sua situação coletiva e não apenas, nem principalmente, em cada um isoladamente; ensina-os a compreender sua força coletiva para sustentar suas reivindicações e enfrentar os conflitos do trabalho. Em síntese, o movimento de greve constitui-se como um dos meios de experiência, aprendizado e formação coletiva dos trabalhadores (Lênin, 1961). Nesse sentido, reforça-se a dimensão da greve como forma de construção de conhecimentos dos trabalhadores no enfrentamento às contradições do trabalho na sociedade capitalista.

No que tange ao procedimento de pesquisa, desenvolveu-se um estudo de base qualitativa que adotou como procedimento de investigação a realização de entrevistas individuais com roteiro semiestruturado e, ainda, o levantamento documental, tendo como principal fonte de investigação a imprensa sindical.

Quanto ao critério de inclusão dos participantes do estudo, optou-se por professores das escolas públicas do município do Rio de Janeiro que atuaram ativamente da greve de 2013, nas assembleias ou em outras atividades do movimento grevista. Inicialmente, realizou-se busca ativa por meio de contato com participantes do movimento pela defesa da saúde no Rio de Janeiro (Fórum de Saúde do Rio de Janeiro) com os quais se tinha facilidade de acesso. Todas as indicações convergiram para o mesmo nome, com quem foi feito contato telefônico e acordado local e data para a entrevista. A partir desta primeira entrevista, foram marcadas outras, empregando-se como critério a indicação sucessiva de cada professor entrevistado. Assim, serviu de inspiração a técnica de pesquisa denominada 'bola de neve' (Dewes, 2013), que, geralmente, é utilizada quando há dificuldade em se encontrar membros de uma população a ser pesquisada.

Ao fim, foram realizadas seis entrevistas (dois professores e quatro professoras) entre os meses de julho e setembro de 2015. Chegou-se a esse número de participantes em razão da dificuldade de localização de trabalhadores que se ajustassem ao perfil do estudo e, ainda, devido ao prazo-limite para a execução do trabalho de campo.

Quanto ao perfil dos entrevistados, todos eram professores pertencentes ao quadro das escolas da rede pública municipal de ensino. Apenas um entrevistado também trabalhava na rede estadual. A faixa etária dos participantes oscilou entre 26 e 55 anos e o tempo de trabalho na rede pública, entre 3 e 20 anos. 
No que concerne à pesquisa documental, foram levantados dados e informações no âmbito da imprensa sindical. Lançou-se mão, principalmente, dos arquivos do periódico denominado Boletins do Sepe, considerando sua relevância e circulação junto à categoria por ocasião das manifestações e atividades do período da greve, ou seja, no segundo semestre de 2013.

Para análise dos materiais de campo, foi escolhida a técnica de análise temática, que consiste em descobrir os núcleos de sentido que compõem uma comunicação, cuja presença ou frequência tenham significado para o objeto analítico visado (Minayo, 2013). Ao final, chegou-se a três temas principais de análise, a saber: trabalho e defesa da educação pública de qualidade; aprendizado coletivo e pedagogia da luta; trabalho e luta pela saúde.

Este estudo recebeu a aprovação do Comitê de Ética em Pesquisa da Escola Nacional de Saúde Pública Sergio Arouca, Fundação Oswaldo Cruz (ENSPFiocruz), sob o número CAAE 44047015.60000.5240.

\section{Trabalho e defesa da educação pública de qualidade}

Com base nas falas dos entrevistados e documentos sindicais, o movimento de greve dos profissionais da educação do município do Rio de Janeiro expressou conflitos relacionados ao trabalho dos professores e à política de educação e gestão nas escolas públicas da rede municipal.

O movimento de greve questionou a meritocracia, modelo de avaliação do trabalho das escolas públicas baseado no Índice de Desenvolvimento da Educação Básica (IDEB) e pautado pela racionalidade mercantil. O IDEB, calculado com base nas taxas de rendimento escolar (aprovação/evasão) e nas médias de desempenho dos exames da Prova Brasil ( $5^{\circ}$ e $9^{\circ}$ anos), classifica as escolas e municípios em todo o Brasil. Na rede de educação municipal do Rio de Janeiro, esse índice é traduzido por metas quantitativas que marcam o trabalho dos professores nas escolas.

(...) os índices viraram parâmetro para tudo! Em todas as prefeituras! As prefeituras mais organizadas, que é o caso do Rio de Janeiro, elas começaram a trabalhar o índice como meta, e começou a pressionar muito o profissional da educação (...) então dá-se a vida pelo índice. Dá-se a vida pelas metas.

O questionamento a respeito da política de meritocracia representa a defesa da autonomia pedagógica dos professores e, ao mesmo tempo, da qualidade do trabalho e do ensino básico no Brasil. A Secretaria Municipal de Educação do Rio de Janeiro fornece 'apostilas' que servem como guia metodológico e suporte à preparação das aulas, chamados de 'cadernos pedagógicos'. De acordo com os relatos, esses cadernos possuem uma qualidade bastante inferior se comparados, por exemplo, ao material fornecido pelo Ministério da 
Educação, já que abordam temas de forma muito resumida e empobrecida. Os professores sentem-se constrangidos a utilizá-los por possuir um conteúdo, explicitamente, correspondente ao da Prova Brasil. Trata-se de uma racionalidade pragmática de ensino, orientada por um modelo gerencial de gestão pública, que não leva em consideração a experiência e o saber dos professores.

O governo cria metas, que são baseadas nos índices. Essas metas elas configuram um modelo de educação que se materializa numa apostila, e o profissional é obrigado a seguir aquela apostila porque, se não, ele é punido tanto na sua carreira, pressionado cotidianamente com ameaça, tem que assinar papelzinho, assinar declaração de que está ciente de um montão de coisas, isso agora virou uma febre no município.

Porque, no apostilamento, você controla o que o profissional vai dar. Você cobra numa prova, você cobra que o profissional dê aquilo e pune quem não trabalha aquele conteúdo.

Além do desempenho nos exames da Prova Brasil, as metas de rendimento nas escolas, expressas em taxas de aprovação, pressionam os professores e geram conflitos no trabalho.

Você tem que passar seu aluno! Porque nós temos um índice de reprovação! Ou então: Ele foi superbem nessa prova aqui! Você tem que passá-lo! Vai ganhar o 14!

Há que se destacar a instauração, pela Prefeitura da Cidade do Rio de Janeiro, da remuneração conhecida como $14^{\circ}$ salário condicionada às metas de desempenho, segundo cada órgão da administração direta. Consoante aos profissionais da educação do município, essa remuneração está condicionada às metas anuais estabelecidas para cada escola. Os trabalhadores acabam pressionados e sentem-se 'fiscalizados' pelos próprios colegas de trabalho a cumprirem as metas para que todos recebam a 'gratificação pela meritocracia'.

Todo mundo em cima de você porque as escolas querem o $14^{\circ}$. (...) Você não é mais pelo aluno, [mas] vamos fazer o máximo pra gente atingir a meta. Parece até empresa privada. Parece até meta de venda.

O esforço para alcance das metas das políticas educacionais nas últimas décadas no Brasil, no contexto de universalização da educação básica, traz uma relativa responsabilização da gestão escolar pela adoção de critérios de eficácia e produtividade (Assunção e Oliveira, 2009). As exigências da gestão passam a pautar a rotina e o trabalho do professor nas escolas. 
(...) são burocracias de rendimento, preencher isso, preencher aquilo, produzir dados para o governo, e você precisa de um ócio, precisa pensar sem ter nada pra pensar e a partir daí seu pensamento elabora uma boa ideia de aula, e não a pressão de com um chicote nas suas costas: 'Produza! Produza!'

O relato expressa conflitos em torno da organização do tempo de trabalho docente. A defesa da efetivação de $1 / 3$ de tempo para o planejamento fora de sala de aula, como previsto na lei n. 11.738, de 16 de julho de 2008 (Brasil, 2008), uma das principais reivindicações do movimento de greve, confronta o prolongamento da jornada e a intensificação do trabalho docente. Para grande parte dos professores da rede municipal do Rio de Janeiro, a jornada de trabalho formal está estabelecida, integralmente, com uma carga horária em sala de aula (inclusive sem pausa entre uma aula e outra), sem incorporar tempo para as múltiplas e crescentes exigências do trabalho docente: relações com a comunidade, tarefas de gestão, participação em conselhos, planejamento do projeto pedagógico e continuidade da formação. Ressalta-se, portanto, a relação da reivindicação para a efetivação de $1 / 3$ de tempo para planejamento, com a defesa da qualidade do processo pedagógico nas escolas públicas.

No tocante ao plano de carreira (com unificação, paridade entre ativos e aposentados; valorização por tempo de trabalho e valorização por formação), antiga reivindicação dos trabalhadores da educação da cidade do Rio de Janeiro, representou um dos principais pontos da pauta do movimento de greve. A concordância da prefeitura em acelerar a construção do plano com a participação do Sepe-RJ, no grupo de trabalho, foi um dos resultados das mobilizações e negociações no primeiro período da greve, então suspensa em 10 de setembro para a elaboração da proposta. Porém, a participação sindical no grupo de trabalho que elaborou a proposta não foi concretizada. Por decisão unilateral, em 17 de setembro de 2013, a prefeitura encaminhou à câmara municipal, em regime de urgência, o projeto de lei n. 442/2013, de criação do Plano de Cargos, Carreira e Remuneração (PCCR), aprovado pela lei n. 5.623, de 01 de outubro de 2013 (Rio de Janeiro, 2013).

Todo esse processo contrariou as expectativas dos professores e demais profissionais da educação, desencadeando o retorno à greve em 20 de setembro. A partir dessa data, a greve foi fortemente reprimida pelo Estado, como nos acontecimentos de 01 de outubro, quando da votação e aprovação do projeto do PCCR pela câmara de vereadores, que amanheceu sitiada pelas forças policiais.

Segundo as falas dos entrevistados e documentos sindicais, o plano aprovado contempla, especialmente, os professores com jornada de trabalho de 40 horas semanais, o correspondente, naquele momento, a menos de $10 \%$ dos trabalhadores da rede municipal de educação. Do mesmo modo, o plano não institui paridade entre ativos e aposentados; não promove a valorização do 
professor pela formação e especialidade obtida. Além disso, o documento insere a possibilidade legal para expansão da chamada polivalência didática, ou seja, a de um professor com formação específica em uma disciplina ministrar aula em outras áreas afins. Pelo prisma de interpretação dos entrevistados e documentos levantados, o não reconhecimento da valorização da formação do professor afeta a qualidade do ensino e a possibilidade da polivalência aprofunda a precarização dos processos de ensino-aprendizagem (Sepe-RJ, 2013b; Pedrosa, 2013; Brito, 2013).

Sem dúvida, constatou-se a importância da questão pedagógica no foco das reivindicações, muitas vezes, prevalecendo sobre a questão salarial.

Não adianta você pagar bem os profissionais se estes profissionais não tiverem valorização. O problema da educação, no geral, é a desvalorização do profissional, não só na questão econômica, mas de não perceber que educação é muito mais do que sala de aula, não permitir que o profissional tenha tempo livre de pesquisar, pensar, planejar, interagir com a sociedade, com os alunos.

Convém reforçar a interpretação dos participantes do estudo acerca da significação da luta principal, qual seja: a defesa da educação pública de qualidade que considere um projeto político democrático que tenha a participação dos profissionais da educação. O movimento de greve foi emblemático na defesa de uma educação pública de qualidade, em contraposição à política meritocrática e seus instrumentos de avaliação que reduzem a educação e os processos pedagógicos a índices e dados estatísticos. Quer dizer, representou a afirmação da educação pública de qualidade como direito social, e não como mercadoria, sem tampouco reduzir o entendimento deste direito como restrito ao acesso às escolas.

Se o Sepe-RJ tem a defesa da educação pública como uma de suas bandeiras históricas, ela ganhou força material durante a greve sustentada pela luta coletiva dos profissionais das escolas. O movimento paredista ganhou as ruas da cidade do Rio de Janeiro em manifestações populares como a do dia 07 de outubro de 2013, em desagravo às ações de repressão do Estado contra os trabalhadores em greve.

Contudo, embora tenha havido importantes manifestações de apoio e solidariedade, a defesa da educação pública de qualidade como direito social permaneceu centrada na mobilização dos profissionais das escolas sem uma incorporação ativa e massiva de amplos segmentos populares e de trabalhadores. Cabe lembrar o desafio colocado por Caldart (2009) para os movimentos sociais ligados à educação: aumentar a pressão pela massificação das lutas pelo envolvimento de outros segmentos sociais e não somente aqueles profissionais que os integram. Dessa forma, é possível mostrar, na prática, o embuste do discurso liberal de universalização do acesso à educação. Importa também 
vincular a luta pela educação pública à defesa de outros direitos sociais que assumam o caráter de luta de classes, aprofundando a contradição instalada.

\section{Aprendizado coletivo e pedagogia da luta}

O exame dos conflitos do trabalho dos professores das escolas públicas, manifestos pelo movimento de greve, de 2013, trouxe sua correlação com a defesa da educação pública de qualidade. No entanto, outro sentido de educação está presente no movimento de greve. Trata-se da educação pelo aprendizado coletivo produzido pelo próprio movimento de greve, uma pedagogia da luta dos trabalhadores ao enfrentar as contradições do trabalho nas escolas.

No ângulo de compreensão da história do movimento dos profissionais da educação, certamente, o ano de 2013 constituiu-se como importante capítulo de sua trajetória, considerando, principalmente, que muitos trabalhadores de escolas do município, do referido período, tinham pouco envolvimento com atividades sindicais ou outro tipo de ações coletivas organizadas. Observe-se que a decisão pela greve, em muitas escolas, partiu dos próprios trabalhadores, sem contar com a presença direta de um representante sindical para convocá-los.

Quando estourou o movimento, o movimento foi além das nossas expectativas, porque muita gente que a gente achava que nunca iria entrar em greve acabou entrando em greve, e as escolas foram parando por uma decisão autônoma da escola. Então foi muito comum você chegar nas escolas sem ter passado nenhum militante da greve e a escola ter fechado, decidiu entrar em greve junto com a massa de profissionais.

O movimento de greve reafirma a luta coletiva como forma de enfrentar a precarização do trabalho, sobrepondo-se às saídas individuais, inclusive com o surgimento, durante a greve, de núcleos e círculos dos professores nas escolas para sustentar a luta para além da direção sindical.

Eu via naquilo ali uma forma de melhorar as nossas condições de trabalho de fato. Então eu acabava levando o que tinha sido decidido na assembleia pra eles no sentido de estimulá-los a continuar a greve sempre! Nunca era no sentido de terminar, sempre era no sentido de continuar e levar o que estava acontecendo para as pessoas que não estavam participando das assembleias (...). Porque quando a gente via algumas pessoas querendo desistir tinha um grupo, no qual eu estava que falava: 'vamos tentar pegar essa pessoa aí e tentar convencer a continuar. Vamos continuar até o fim'. Essa era a nossa posição, de continuar até onde não desse mais. Até quando a assembleia quisesse terminar a greve. 
Esses núcleos e círculos informais nas escolas foram cruciais para que o movimento enfrentasse o temor diante das ameaças de retaliações dos gestores do município e as investidas repressoras contra as mobilizações dos professores. Nesse ponto, convém lembrar a importância da organização por locais de trabalho como aspecto fundamental de defesa da saúde e do próprio trabalho. Essa forma de operar deveria fazer parte do dia a dia das escolas, mantendose, inclusive, após o período de greve. Este movimento representou o reencontro dos profissionais da educação com o sentido coletivo do trabalho, por estarem reunidos e solidários na luta, com a possibilidade de compartilhar e de enfrentar o sofrimento, a angústia e o medo.

Cada dia foi muito tenso. Se a assembleia decidisse pelo fim da greve, eu voltaria; se não, eu continuaria, mesmo com medo. Tanto que eu fui até o final.

Segundo os entrevistados, a vivência do período da greve foi intensa, inclusive por entrarem em contato com diferentes posições sindicais, de partidos políticos e de outros movimentos considerados 'independentes'. Freire e Shor (1986) asseguram que, na intimidade dos movimentos sociais, que visam a transformações, encontra-se a dinâmica da mudança social de cunho pedagógico. Em última análise, a libertação e a emancipação são atos sociais, "nós mudamos à medida que nos engajamos no processo de mudança social" (p. 214). Consoante à vertente freireana, a transformação da sociedade como um todo exige o desenvolvimento da percepção crítica da realidade e a experiência de participação nos movimentos de lutas democráticas, considerando que essa experiência acrescenta profundidade ao conhecimento acerca do mundo real e se efetua em contextos fora da sala de aula.

O movimento de luta revelou-se para os trabalhadores como aprendizado que amplia a autoconfiança e desempenhou um trabalho pedagógico que é vital à classe trabalhadora (Badaró-Mattos, 2013).

No decurso das entrevistas, ficou evidente o sentido pedagógico atribuído ao movimento. De acordo com Mészáros (2005), a educação, na perspectiva da luta emancipatória, deve recuperar os vínculos concretos entre trabalho e educação no contexto das relações capitalistas. Para o autor, educação significa produção de insubordinação e rebeldia ao sistema que explora o trabalho, transforma a educação em mercadoria e aprofunda a desigualdade social. Convergente com esta acepção, Caldart (2009) assevera que a educação política de caráter emancipatório se realiza no cerne do movimento de luta da classe trabalhadora. Trata-se de uma perspectiva ampliada de educação e de práxis pedagógica que se processa na luta e experiência coletiva do trabalho. 


\section{Trabalho e luta pela saúde}

Anteriormente, destacou-se a relação entre os questionamentos dos conflitos do trabalho nas escolas pelo movimento de greve dos professores com a defesa da educação pública de qualidade. Igualmente, essa resistência também está relacionada à saúde no trabalho docente, embora não explicitada na pauta da greve apresentada pelo Sepe-RJ. É o que se pode extrair das falas dos entrevistados, na qual a greve aparece em defesa da qualidade do trabalho e, simultaneamente, da saúde. Quer dizer, o questionamento à política meritocrática e à defesa da autonomia pedagógica, a reivindicação de $1 / 3$ do tempo para atividades de planejamento e de um plano de carreira que valorize o trabalho docente aparecem como condição de qualidade do trabalho docente e, também, da saúde. Trabalho e saúde são vistos como indissociáveis. Ou, mais precisamente, a luta pela melhoria da qualidade do trabalho docente é considerada pelos professores como luta pela saúde:

(...) a gente está lutando por melhores condições de trabalho, de saúde. Muito mais o trabalho relacionado diretamente à saúde. Não tem como separar as duas coisas.

Na Saúde Coletiva, a literatura corrobora o entendimento do processo saúde-doença dos trabalhadores produzido pelo processo de trabalho (Laurell e Noriega, 1989). Assim, os relatos e a pauta do movimento de greve como, por exemplo, a defesa de $1 / 3$ da carga horária para planejamento, confronta o prolongamento e a intensificação do tempo de trabalho docente que comprometem a saúde destes trabalhadores (Assunção e Oliveira, 2009). A intensificação do trabalho na determinação do processo saúde-doença dos professores também compreende a pressão para aumentar a produtividade com imposição de constrangimento temporal, tanto mais quando parcelas da remuneração estão condicionadas às metas de desempenho e aos critérios de avaliação do trabalho nas escolas (Assunção e Oliveira, 2009; Pina e Stotz, 2014).

Os relatos dos entrevistados relacionaram esse processo às exigências da gestão nas escolas decorrentes das políticas educacionais, por sua vez, implicadas aos problemas de saúde dos profissionais da educação (Souza e Brito, 2013). As autoras ressaltam a importância de um processo de trabalho gerido por uma gestão democrática como fator positivo para driblar os problemas trazidos pela política educacional nas últimas décadas. Destacam, ainda, o quão é fundamental para a saúde os intervalos durante a jornada, o tempo de planejamento, bem como a criação de espaços para discussões coletivas, transformando a experiência no trabalho escolar em uma situação de aprendizagem constante. 
Para os entrevistados, a greve teve um significado de mudança, considerando que foi o momento em que puderam refletir coletivamente e de forma crítica sobre o trabalho em escolas e sua relação com a saúde.

Você começa a conversar com as pessoas e elas começam a ter consciência do que elas têm, foi o seu trabalho que te deu de presente (...) Agora, eu tenho ciência de que isso afeta minha saúde física e mental, e eu não posso continuar no mesmo. Se eu ganho pouco, eu tenho poucas condições de comprar um remédio, tenho pouco tempo com minha família, minhas cordas vocais não aguentam e aí você começa (...) pra mim, a greve foi esta conscientização mesmo!

O processo de greve e as manifestações dos professores foram uma oportunidade de mudar a forma com que muitos dos trabalhadores enxergavam o trabalho, sua gestão, as relações sociais nele estabelecidas e seus efeitos sobre a saúde.

No entanto, a luta pela saúde não constitui um processo linear e exclusivamente objetivo, nem tampouco redutível a uma ação individual. As falas apontaram dimensões subjetivas relacionadas à tensão e ao medo vivenciados durante a greve, em que a mobilização individual para seu enfrentamento tem seu fundamento no coletivo em luta.

Pra mim, foi muito tenso. Eu tinha muito medo. Eu tinha medo. (...) Mas eu jamais conseguiria, nesse momento de luta, ir pra escola como se tudo estivesse bem, ignorar os meus colegas que estavam lutando pela gente e pelos alunos.

Com o fim da greve, os professores também relataram terem tido dificuldades no retorno ao trabalho, especialmente pelo acirramento de conflitos interpessoais e antagonismos com as direções das escolas. Houve relatos de sintomas de depressão e de muito 'desgaste' pessoal.

(...) ao mesmo tempo, a greve fez muita gente ficar doente. Eu conheço muita gente que se decepcionou tanto com aquela greve, que se decepcionou tanto com o que o governo fez com a aprovação do PCCR, quanto com o que os colegas fizeram quando resolveram sair da greve.

Além da frustração com as negativas do governo municipal em atender às reivindicações da categoria, interpreta-se que, ao retornarem para as suas atividades, os professores se veem diante do mesmo processo de gestão e organização do trabalho nas escolas, com poucas modificações do ponto de vista dos problemas de saúde a ele relacionados. Foi relatado que muitos 
trabalhadores não suportaram retornar à mesma situação de trabalho nas escolas, então identificada como nociva à saúde. Pode-se fazer um paralelo com a recusa do trabalhador em retornar ao mesmo ambiente ou função após afastamento por acidente ou doença do trabalho, tal qual mostra o estudo de Glina e colaboradores (2001).

Em termos concretos, muitas das defesas individuais, que até então preservavam certa normalidade e mantinham o professor trabalhando nas escolas, foram postas em xeque pelo movimento de greve.

Nessa linha de interpretação, o movimento de greve proporcionou, de um lado, a possibilidade do questionamento do trabalho e de muitos agravos à saúde a ele relacionados, significando mudança para muitos profissionais da educação. Por outro lado, trouxe dificuldades para o retorno e continuidade do trabalho, mantidas as condições nocivas à saúde. Nesse caso, importa considerar a capacidade coletiva para enfrentar o sofrimento e proteger a saúde no cotidiano do trabalho na escola. Logo, essa perspectiva supõe superar a natureza difusa dos núcleos e círculos dos professores formados nas escolas durante a greve para uma configuração mais estruturante do ponto de vista da saúde e da organização por locais de trabalho.

Sem dúvida, esse processo contraditório da experiência do movimento de greve, elaborado com base na reflexão dos participantes desta pesquisa, assevera a dimensão da luta coletiva como lócus de construção de conhecimento e intervenção em saúde pelos trabalhadores. Certamente, tal dimensão merece ser valorizada pela pesquisa científica e pela organização sindical dos trabalhadores, tal como observado por Oddone (2007).

\section{Considerações finais}

Ao refletir sobre os resultados deste estudo, conclui-se que a greve dos professores da rede municipal do Rio de Janeiro de 2013 constituiu um movimento de questionamento aberto da situação do trabalho nas escolas e materializou-se como espaço de luta em defesa da educação pública de qualidade. Por certo, configurou-se como processo de aprendizagem sob a perspectiva da pedagogia política para o processo de formação dos trabalhadores, adquirindo importância para a construção de conhecimento e intervenção em saúde.

Cabe concluir, também, que o movimento de greve foi categórico em se contrapor à política de meritocracia e seus instrumentos de avaliação que não levam em consideração a experiência no trabalho escolar como uma situação de aprendizagem contínua. Além disso, este estudo possibilitou o entendimento de conflitos em torno da organização do tempo de trabalho docente como o prolongamento da jornada e a intensificação do trabalho. Assim, ressalta-se 
a importância de se efetivar políticas que tornem realidade a reivindicação de $1 / 3$ de tempo na jornada de trabalho do professor para planejamento das atividades pedagógicas e, ainda, a valorização por tempo de trabalho e por formação profissional continuada.

Observou-se que as entrevistas tornaram-se momentos de reflexão a respeito do próprio trabalho dos entrevistados. A relação e a interação entre entrevistado e pesquisador proporcionaram importantes elaborações acerca da relação entre trabalho, educação e saúde a partir da experiência da luta coletiva dos professores.

Contudo, sabe-se que a saúde não se constitui em uma bandeira tradicional na agenda de lutas sindical, ainda que o Sepe-RJ tenha adotado esse tema como matéria política desde os anos noventa, incluindo a realização de duas conferências de saúde (Souza e Brito, 2012; Souza et al., 2003). E, embora não explicitada na pauta da greve apresentada pelo Sepe-RJ, este estudo possibilitou esboçar a relação trabalho-saúde a partir da reflexão dos entrevistados, ressaltando sua relevância no cotidiano dos profissionais da educação e suas organizações - e, portanto, não circunscrito aos momentos de luta aberta.

Por fim, é válido mencionar Oddone e colaboradores (1986), segundo os quais os avanços reais só são possíveis quando a academia faz mais do que apenas escutar o trabalhador e o inclui como sujeito do processo de produção de conhecimento e das mudanças em seu processo de trabalho. Isso significa a inclusão do saber do trabalhador e de sua experiência como parte integrante do conhecimento científico em saúde.

\section{Colaboradores}

Laís Oliveira de Souza participou da concepção do estudo, realizou pesquisa de campo, coleta e análise dos dados, redação da primeira versão do manuscrito e aprovação da versão final. José Augusto Pina participou da concepção e orientação do estudo, análise dos dados, revisão da redação do manuscrito e aprovação da versão final. Kátia Reis de Souza participou da concepção e orientação geral do estudo, análise dos dados, revisão da redação do manuscrito e aprovação da versão final. 


\section{RESITENCIA Y PRÁXIS EN LA HUELGA DE LOS PROFESORES DE LA RED PÚBLICA MUNICIPAL DE RIO DE JANEIRO}

Resumen Este estudio tiene por objetivo analizar las relaciones entre trabajo, educación y salud en la huelga de los profesionales de educación de la red municipal de Rio de Janeiro, ocurrida en el año 2013. Se trata de una encuesta cualitativa, la cual adoptó, como técnica de investigación, la realización de entrevistas individuales y la búsqueda documental, con base en la prensa sindical. En lo que respecta al análisis de los materiales de campo, fue elegida la técnica de análisis temática, siendo identificados tres temas principales de interpretación: trabajo y defensa de la educación pública de calidad; aprendizaje colectivo y pedagogía de la lucha; y lucha colectiva por la salud. En el ángulo de comprensión de la historia, la huelga se materializó como espacio de cuestionamiento acerca de la situación del trabajo en las escuelas y como movimiento de lucha en defensa de la educación pública de calidad. Del mismo modo, la huelga trajo reflexiones acerca de la relación entre el trabajo docente y la lucha por la salud. Concluye que las acciones colectivas de trabajadores son espacios de aprendizaje, de producción de conocimiento e intervención en salud. Se trata de una perspectiva ampliada de educación y salud, como praxis pedagógica, que se procesa en la lucha y en la valorización de la experiencia colectiva del trabajo.

Palavras clave salud del trabajador; profesores; educación pública; sindicato; huelga.

\section{Referências}

ASSUNÇÃO, Ada Á.; OLIVEIRA, Dalila A. Intensificação dos trabalhos e saúde dos professores. Educação \& Sociedade, Campinas, v. 30, n. 107, p. 349-372, 2009.

BADARÓ-MATTOS, Marcelo. Uma greve, várias lições: a greve das universidades federais no Brasil em 2012. Revista Iberoamericana de Educación Superior, México, v. 4, n. 10, p.135142, 2013.

BRAGA, Ruy. A rebeldia do precariado: trabalho e neoliberalismo no Sul global. São Paulo: Boitempo, 2017.

BRASIL. Lei n. 11.738, de 16 de julho de 2008. Regulamenta a alínea " $\mathrm{e}$ " do inciso III do caput do art. 60 do Ato das Disposições Constitucionais Transitórias, para instituir o piso salarial profissional nacional para os profissionais do magistério público da educação básica. Diário Oficial da República Federativa do Brasil, Poder Executivo, Brasília, DF, 17 jul. 2008. Disponível em: < http://www.planalto.gov.br/ccivil_03/_ato2007-2010/2008/ lei/111738.htm>. Acesso em: 20 ago. 2018.
BREILH, Jaime. Nuevos conceptos y técnicas de investigación: guía pedagógica para un taller de metodología. 2. ed. Quito: Centro de Estudios y Asesoría en Salud - CEAS, 1995.

BRITO, Gabriel. A questão pedagógica está no foco dos professores e é até maior que a salarial. Correio da Cidadania, 23 out. 2013. Disponível em: < http://www.correiocidadania. com.br/index.php?option=com_content $\&$ vie $\mathrm{w}=$ article\&id $=8981$ :submanchete231013\&cat $\mathrm{id}=63$ : brasil-nas-ruas $\&$ Itemid $=200>$. Acesso em: 4 mar. 2018.

BRITO, Jussara; ATHAYDE, Milton. Trabalho, educação e saúde: o ponto de vista enigmático da atividade. Trabalho, Educação e Saúde, Rio de Janeiro, v. 1, n. 2, p. 239-266, 2003.

CALDART, Roseli S. Educação do campo: notas para uma análise de percurso. Trabalho, Educação e Saúde, Rio de Janeiro, v. 7, n. 1, p. 35-64, 2009.

DEWES, João O. Amostragem em Bola de Neve e Respondent-Driven Sampling: uma descrição 
de métodos. 2013. 52 f. Monografia (Graduação em Matemática) - Universidade Federal do Rio Grande do Sul, Porto Alegre, 2013.

FREIRE, Paulo; SHOR, Ira. Medo e ousadia: o cotidiano do professor. Rio de Janeiro: Paz e Terra, 1986.

GLINA, Débora M. R. et al. Saúde mental e trabalho: uma reflexão sobre o nexo com o trabalho e o diagnóstico, com base na prática. Cadernos de Saúde Pública, Rio de Janeiro, v. 17, n. 3, p. 607-616, 2001.

GOMES, Luciana; BRITO, Jussara C. Desafios e possibilidades ao trabalho docente e à sua relação com a saúde. Estudos e Pesquisa em Psicologia, Rio de Janeiro, v. 6, n. 1, p. 49-62, 2006.

LAURELL, Asa C. Saúde e trabalho: os enfoques teóricos. In: NUNES, Everardo D. (org). As Ciências Sociais em saúde na América Latina: tendências e perspectivas. Brasília: Opas, 1985. p. $255-272$.

LAURELl, Asa C.; NORIEGA, Mariano. Processo de produção e saúde: trabalho e desgaste operário. São Paulo: Hucitec, 1989.

LEHER, Roberto; VITTORIA, Paolo; MOTTA, Vânia. Educação e mercantilização em meio à tormenta político-econômica do Brasil. Germinal: Marxismo e Educação em Debate, v. 9, p. 14-24, 2017.

LÊNIN, Vladimir I. Sobre as greves. In: LÊNIN Vladimir I. (org.). Os sindicatos. Rio de Janeiro: Editorial Vitória, 1961. p. 39-47.

MARCHIORI, Flávia; BARROS, Maria E.; OLIVEIRA, Sonia P. Atividade de trabalho e saúde dos professores: o programa de formação como estratégia de intervenção nas escolas. Trabalho, Educação e Saúde, Rio de Janeiro, v. 3, n. 1, p. 143-170, 2005.

MASCARELLO, Marinete R. P.; BARROS, Maria E. B. Nos fios de Ariádne: cartografia da relação saúde-trabalho numa escola pública de Vitória-ES. Revista Brasileira de Educação, Rio de Janeiro, v. 12, n. 34, p. 23-33, 2007.
MÉSZÁROS, István. A educação para além do capital. São Paulo: Boitempo, 2005.

MINAYO, Maria C. S. O desafio do conhecimento. São Paulo: Hucitec; Rio de Janeiro: Abrasco, 2013.

NEVES, Mary Y. R.; SILVA, Edith S. A dor e a delícia de ser (estar) professora: trabalho docente e saúde mental. Estudos e Pesquisa em Psicologia, Rio de Janeiro, v. 6, n. 1, p. 63-75, 2006.

ODDONE, Ivar et al. Ambiente de trabalho: a luta dos trabalhadores pela Saúde. São Paulo: Hucitec, 1986.

ODDONE, Ivar. Reflexiones sobre el modelo obrero italiano. Revista Sindical Salud, Trabajo y Medio Ambiente, Lima, v. 2, n. 5, p. 4-8, 2007.

PEDROSA, Silvio. Greve dos professores: "não é apenas por salário". Entrevista especial com Silvio Pedrosa. Porto Alegre: Instituto Humanitas Unisinos - IHU, 8 de outubro de 2013. Disponível em: <http://www.ihu.unisinos. br/159-noticias/entrevistas/524470-grevedos-professores-nao-e-apenas-por-salarioentrevista-especial-com-silvio-pedrosa $>$. Acesso em: 27 fev. 2018.

PINA, José A.; STOTZ, Eduardo. Intensificação do trabalho e saúde do trabalhador: uma abordagem teórica. Revista Brasileira de Saúde Ocupacional. São Paulo, v. 39, n. 130, p. 150-160, 2014.

RIO DE JANEIRO (Município). Lei n. 5623, de 1 de outubro de 2013. Dispõe sobre o Plano de Cargos, Carreiras e Remuneração dos funcionários da Secretaria Municipal de Educação e dá outras providências. Diário da Câmara Municipal do Rio de Janeiro, Rio de Janeiro, 3 out. 2013. Disponível em: < http://mail.camara. rj.gov.br/APL/Legislativos/contlei.nsf/7cb7d 306c2b748cb0325796000610ad8/d80e5d992b 53402803257 bf90059dc60?OpenDocument $>$. Acesso em: 20 ago. 2018.

SINDICATO ESTADUAL DOS PROFISSIONAIS DE EDUCAÇÃO DO RIO DE JANEIRO 
(Sepe). Boletim do Sepe: Rede Municipal. Rio de Janeiro, 9 de agosto de 2013a. Disponível em: <http://www.Seperj.org.br/admin/ fotos/boletim/boletim262.pdf $>$. Acesso em: 2 mar. 2018.

SINDICATO ESTADUAL DOS PROFISSIONAIS DE EDUCAÇÃO DO RIO DE JANEIRO

(Sepe). Boletim do Sepe: Rede Municipal. Rio de Janeiro, 24 de setembro de 2013b. Disponível em: <http://www.Seperj.org.br/admin/ fotos/boletim/boletim328.pdf $>$. Acesso em 2 mar. 2018.

SOUZA, Katia R. et al. A trajetória do Sindicato Estadual dos Profissionais da Educação do Rio de Janeiro (Sepe-RJ) na luta pela saúde no trabalho. Ciência \& Saúde Coletiva, Rio de Janeiro, v. 8, n.4, p. 1.057-1.068, 2003.

SOUZA, Katia R. Mudanças necessárias no trabalho em escolas: a visão dos profissionais da educação e o enfoque da saúde do trabalhador. Educação em Revista, Belo Horizonte, v. 30, p. 291-313, 2014.

SOUZA, Kátia R.; BRITO, Jussara C. Gestão do trabalho, educação e saúde: análise de uma experiência de mudança em escola pública. Educação \& Sociedade, Campinas, v. 34, p. 267-283, 2013.

SOUZA, Katia R.; BRITO, Jussara C. Sindicalismo, condições de trabalho e saúde: a perspectiva dos profissionais de saúde do Rio de Janeiro. Ciência \& Saúde Coletiva, Rio de Janeiro, v. 17, n. 2, p. 379-388, 2012.

SOUZA, Katia R.; ROZEMBERG, Brani. As macropolíticas educacionais e a micropolítica de gestão escolar: repercussões na saúde dos trabalhadores. Educação e Pesquisa, São Paulo, v. 39, p. 433-447, 2013. 